\title{
Lung function measurements in young children with spinal muscle atrophy; a cross sectional survey on the effect of position and bracing
}

\author{
S E Tangsrud, K C Lødrup Carlsen, I Lund-Petersen, K-H Carlsen
}

\begin{abstract}
Background-Spinal muscular atrophy (SMA) affects respiratory muscles, which in addition to progressive scoliosis leads to respiratory impairment. Children with developing scoliosis are usually treated with spinal bracing to delay the progress. Aims-To assess the impact of body position and application of spinal bracing on lung function during tidal breathing in children with SMA.

Methods-Lung function was determined by tidal flow volume loops and passive respiratory mechanics (single breath occlusion technique) in all eight children in southern Norway with SMA type I and II, in both the sitting and supine position. Additional measurements were performed with and without bracing in five children. Muscle strength was assessed by the Brooks scale.

Results-Tidal expiratory volume $\left(\mathrm{V}_{\mathrm{E}}\right)$ and compliance of the respiratory system (CRS) tended to be higher in the sitting compared to the supine position, but this was not statistically significant. However, applying bracing in the sitting position significantly reduced $V_{E}$. The highest values of CRS and $V_{E}$ were found in the sitting position without bracing.

Conclusion-Impairment of tidal respiration must be considered when applying spinal bracing in very young children developing scoliosis with SMA. (Arch Dis Child 2001;84:521-524)
\end{abstract}

Keywords: spinal muscular atrophy; lung function; tidal breathing; spinal bracing

Department of Paediatrics, Woman and Child Clinic, Ullevål Hospital, N-0407 Oslo, Norway S E Tangsrud K C Lødrup Carlsen I Lund-Petersen

Voksentoppen Centre for Children with Asthma, Allergy and Chronic Lung

Diseases, Ullveien 14, 0791 Oslo, Norway K-H Carlsen

Correspondence to: Dr Tangsrud svein-erik.tangsrud@ulleval.no

Accepted 16 January 2001
Spinal muscle atrophy (SMA) is a crippling disease in childhood, which eventually leads to pulmonary complications and early death in those most severely affected. ${ }^{1}$ The disease is rare, with a prevalence of $4.17 \times 10^{5}$ in children younger than 18 years. ${ }^{2}$

Thus, in the entire southern part of Norway (total population of approximately 2.2 million), only nine children under the age of 8 years were known to suffer from SMA at the time of the study.

On a clinical basis the subgrouping of three stages is now widely accepted. ${ }^{3}$ Type I (Werdnig Hoffman) patients are the most severely affected, with symptoms presenting from birth to 6 months; they are never able to sit or stand. Children with the intermediate form, type II (Dubowitz form), develop symptoms during the first 6-18 months. They are able to sit without support, but cannot walk. Type III (Kugelberg Welander) patients are able to stand and walk; symptoms before the age of 18 months are unusual.

SMA type I is associated with impairment of respiratory function, which is probably caused by involvement of the intercostal muscles as well as the diaphragm. ${ }^{4}$ Death as a result of respiratory insufficiency within the first 18 months of life is common. Type II SMA is more heterogeneous in this respect, but respiratory function is the single most important factor in determining prognosis. Type III affected children have no respiratory problems. Both type I and type II patients tend to develop scoliosis and other vertebral deformities. Scoliosis contributes to the impaired lung function ${ }^{1}$ by physically impeding respiratory movement and thereby reducing vital capacity, as well as increasing ventilation/perfusion mismatch. ${ }^{5}$

Spinal bracing (wearing a rigid jacket) delays progression of the columnar deformity curves. ${ }^{67}$ However, this causes appreciable respiratory impairment, with significant reductions in vital capacity ${ }^{4}$ in children with severe scoliosis.

Monitoring ventilation in these patients is therefore of great importance. Until recently, measurements of lung function have been limited in very young children not able to cooperate with conventional methods, such as spirometry. However, in the last decade, measurements of tidal flow volume (TFV) loops as well as passive (static) respiratory mechanics have become available in the clinical setting, with the availability of commercially produced equipment. TFV loops are well described in other lung diseases in infants and young children, ${ }^{8}$ but have not been reported to any extent in neuromuscular disease.

Signs and symptoms of respiratory impediment by bracing may be subtle and difficult to interpret, particularly in children too young to convey appropriately any discomfort this may generate. Reduction of vital capacity from the sitting to the supine position is alleged to be a sign of diaphragm weakness. However, little is known about the effect on tidal breathing of positional changes in young children with SMA type I and II.

The aims of the present study were therefore to assess whether positional changes influence tidal breathing; and secondly, to assess possible effects of fitted spinal bracing on tidal breathing in very young children with SMA.

Subjects and methods SUBJECTS

All children under 8 years with SMA in southern Norway were included in the present study (see 
Table 1 Description of eight patients with spinal muscular atrophy

\begin{tabular}{|c|c|c|c|c|c|c|c|c|c|c|}
\hline \multirow[b]{2}{*}{ Subject } & \multirow[b]{2}{*}{ Sex } & \multirow[b]{2}{*}{ Age (mth) } & \multirow[b]{2}{*}{ Bracing } & \multirow[b]{2}{*}{$\begin{array}{l}S M A \\
\text { type }\end{array}$} & \multirow[b]{2}{*}{$\begin{array}{l}\text { Weight } \\
\text { (kg) }\end{array}$} & \multirow[b]{2}{*}{$\begin{array}{l}\text { Length } \\
\text { (cm) }\end{array}$} & \multirow[b]{2}{*}{$\begin{array}{l}\text { Cobb's } \\
\text { angle }\end{array}$} & \multicolumn{3}{|c|}{ Brooks scale } \\
\hline & & & & & & & & $L L$ & $U L$ & $B F$ \\
\hline 1 & $\mathrm{~F}$ & 90 & + & 2 & 20.0 & 118 & 45 & 8 & 4 & 1 \\
\hline 2 & $M$ & 85 & + & 2 & 22.0 & 115 & 35 & 9 & 4 & 1 \\
\hline 3 & $\mathrm{~F}$ & 47 & & 1 & 8.3 & 100 & 108 & 9 & 5 & 1 \\
\hline 4 & $\mathrm{~F}$ & 62 & + & 2 & 4.0 & 99 & 9 & 8 & 4 & 1 \\
\hline 5 & $\mathrm{~F}$ & 48 & + & 2 & 11.6 & 94 & 10 & 8 & 5 & 1 \\
\hline 6 & $\mathrm{~F}$ & 35 & & 1 & 12.0 & 100 & 10 & 8 & 6 & 1 \\
\hline 7 & $\mathrm{~F}$ & 34 & & 2 & 11.5 & 99 & 0 & 2 & 2 & 1 \\
\hline 8 & $M$ & 43 & + & 2 & 12.3 & 100 & 27 & 8 & 5 & 1 \\
\hline
\end{tabular}

LL, lower limb; UL, upper limb; BF, bulbar function.

table 1). Two patients died during the study period and were not included. Diagnosis was confirmed in all patients by extensive examination (including clinical, genetic, and neurophysiological examination), as well as by muscle biopsy. All eight patients had SMA type I or II. Mean age at inclusion was 60.7 months (range 34-90). Five children had a lightweight rigid polypropylene supporting brace to control their scoliosis.

The subjects were included after informed consent by their parents, and the study was approved by the regional medical ethics committee.

\section{METHODS}

Clinical assessment

Functional status of the children was assessed using the Brooks graded scale $(0-10)$ for function of lower/upper limb and bulbar nerves. ${ }^{9}$ This scale was originally developed for assessing muscle function in children with Duchenne muscular atrophy. However, this has also been found valuable in assessing muscular function in children with SMA. The five children with bracing were assessed with and without their brace, using radiographs taken in the sitting position for measurement of Cobb's angle. ${ }^{9}$ Muscle power was assessed clinically using a scale from 1 to $5 .^{10}$

\section{Lung function measurements}

Lung function was measured in all children when awake, in the sitting and supine positions. The effect of bracing on lung function was measured in the five children by performing measurements in the sitting and supine positions with and without bracing.

TFV loops were measured using the SensorMedics 2600 system (California, USA), described in detail elsewhere. ${ }^{11}{ }^{12}$ In brief, the 2600 consists of an IBM-PS2/50Z (8086) computer with an outboard microprocessor controlled (8085) analogue to digital conversion module. Flow was measured using a triple screen pneumotachograph (Hans Rudolph, Missouri, USA; 4500 series), with a flow range of 0-30 litres per minute. Differential pneumotach pressure and mouth pressure were measured with Validyn DP-250 transducers (commercial versions of the MP-45) at $\pm 2 \mathrm{~cm}$ $\mathrm{H}_{2} \mathrm{O}$ and $\pm 100 \mathrm{~cm} \mathrm{H}_{2} \mathrm{O}$ respectively. The pneumotach was fitted to a close fitting mask with an inflated cuff of an appropriate size for each infant. Integration of flow to volume was done at a rate of 256 samples per second without any filtering of the raw signal. TFV loops were recorded in groups of four (from eight sampled curves) according to a standard procedure, ${ }^{13}$ and the mean parameters of these four loops were used for analysis.

Respiratory system mechanics were measured by the single breath, passive exhalation technique. ${ }^{11}$ Automatic occlusion of the airway at end inspiration with the system's pneumatic slide valve was initiated following several breaths to establish a stable baseline. Occlusion was maintained until relaxation of the respiratory system against the shutter was verified by the computer, recording a plateau pressure for 100 milliseconds. A plateau was considered to be valid if pressure variation was less than $\pm 0.125 \mathrm{~cm} \mathrm{H}_{2} \mathrm{O}$ for the duration of the plateau. On shutter opening, the passive expiratory flow volume loop was stored for measurements. A linear segment, late in the decelerating flow volume curve, was selected and a least squares best fit line was drawn and extended to cross the volume axis at zero flow and the flow axis at zero volume.

Respiratory system compliance (CRS) was calculated from the volume intercept (VVT) and plateau pressure, and the resistance (RRS) from the flow intercept (VO) and plateau pressure. The time constant of the respiratory system (TRS) was recorded as the slope of the best fit line.

At least six acceptable, consecutive CRS/ RRS measurements were attempted during each test (three to seven acceptable curves), the reported values being means of the accepted curves.

Real time analysis of the recorded data was performed by the SensorMedics system.

\section{STATISTICAL ANALYSIS}

Statistical analysis was performed using a personal computer and the Statistical Package for Social Sciences (SPSS). All tests were done with two tails; differences were considered to be statistically significant at $\mathrm{p}<0.05$. Analyses for possible differences in measurements within subjects were performed by paired tests and the Wilcoxon signed ranks test for matched pairs. Results are given as mean (SD) unless otherwise stated.

\section{Results}

Table 2 presents results of lung function measurements. One patient ( $\mathrm{LH})$ did not cooperate after the first measurement; no comparisons related to position were subsequently possible (she did not have a bracing at the time).

EFFECT OF POSITION WITHOUT BRACING

Mean $\mathrm{V}_{\mathrm{E}} / \mathrm{kg}$ was higher in the sitting $(9.5 \mathrm{ml})$ compared to the supine $(8.8 \mathrm{ml})$ position (NS). Position did not affect $t_{\mathrm{PTEF}} / t_{\mathrm{E}}$ (time to reach peak tidal expiratory flow to total expiratory time). CRS/kg was also higher when comparing the sitting to the supine position, although not significantly so $(p=0.068)$. 
Table 2 Lung function in eight children with spinal muscle atrophy

\begin{tabular}{llllll}
\hline & $\begin{array}{l}\text { Respiratory } \\
\text { rate(breaths/min) }\end{array}$ & $V_{E} / \mathrm{kg}(\mathrm{ml})$ & $t_{\text {PTEF }} / \mathrm{t}_{E}$ & $\begin{array}{l}\mathrm{CRS} / \mathrm{kg} \\
\left(\mathrm{ml} / \mathrm{cm} \mathrm{H} \mathrm{H}_{2} \mathrm{O} / \mathrm{kg}\right)\end{array}$ & $\begin{array}{l}\mathrm{RRS} / \mathrm{kg} \\
\left(\mathrm{cm} \mathrm{H} \mathrm{H}_{2} \mathrm{O} / \mathrm{ml} / \mathrm{s}\right)\end{array}$ \\
\hline Sitting + & $\begin{array}{l}40.8(13.6) \\
(\mathrm{n}=5)\end{array}$ & $\begin{array}{l}8.0(2.2) \\
(\mathrm{n}=5)\end{array}$ & $\begin{array}{l}0.20(0.06) \\
(\mathrm{n}=5)\end{array}$ & $\begin{array}{l}0.97(0.37) \\
(\mathrm{n}=4)\end{array}$ & $\begin{array}{l}0.15(0.007) \\
(\mathrm{n}=4)\end{array}$ \\
Sitting - & $\begin{array}{l}0.6(8.53) \\
(\mathrm{n}=8)\end{array}$ & $\begin{array}{l}9.5(2.5) \\
(\mathrm{n}=8)\end{array}$ & $\begin{array}{l}0.21(0.07) \\
(\mathrm{n}=8)\end{array}$ & $\begin{array}{l}1.56(0.55) \\
(\mathrm{n}=6)\end{array}$ & $\begin{array}{l}0.3(0.040) \\
(\mathrm{n}=6)\end{array}$ \\
Supine + & $\begin{array}{l}4.0(14.7) \\
(\mathrm{n}=4)\end{array}$ & $\begin{array}{l}8.8(3.1) \\
(\mathrm{n}=4)\end{array}$ & $\begin{array}{l}0.22(0.04) \\
(\mathrm{n}=4)\end{array}$ & $\begin{array}{l}0.83(0.04) \\
(\mathrm{n}=2)\end{array}$ & $\begin{array}{l}0.25(0.002) \\
(\mathrm{n}=2)\end{array}$ \\
Supine - & $\begin{array}{l}33.2(10.0) \\
(\mathrm{n}=5)\end{array}$ & $\begin{array}{l}8.8(5.4) \\
(\mathrm{n}=5)\end{array}$ & $\begin{array}{l}0.21(0.08) \\
(\mathrm{n}=5)\end{array}$ & $\begin{array}{l}1.41(0.57) \\
(\mathrm{n}=4)\end{array}$ & $\begin{array}{l}0.12(0.005) \\
(\mathrm{n}=4)\end{array}$ \\
\hline
\end{tabular}

$+/-$ indicates with $(+)$ and without $(-)$ bracing, respectively.

$\mathrm{V}_{\mathrm{E}}$, tidal expiratory volume; $t_{\mathrm{PTEF}} / t_{\mathrm{E}}$, time to reach peak tidal expiratory flow to total expiratory time; CRS, compliance of the respiratory system; RRS, resistance of the respiratory system.

EFFECT OF BRACING

Lung function was significantly affected by bracing. $\mathrm{V}_{\mathrm{E}} / \mathrm{kg}$ was higher in the sitting position without bracing compared to all other situations. In the sitting position $\mathrm{V}_{\mathrm{E}} / \mathrm{kg}$ was significantly higher without bracing compared to with bracing ( $\mathrm{p}=0.04$; fig $1 \mathrm{~A})$. Respiratory rate also tended to increase with bracing in the sitting position, but this did not reach statistical significance $(p=0.08)$. There was no significant effect of bracing on the time-flow ratio $t_{\mathrm{PTEF}} / t_{\mathrm{E}}$ (time to reach peak expiratory flow to total respiratory time).

Passive respiratory mechanics were successful in at least one measurement in six of the patients. CRS/kg was higher without bracing in the sitting position, although this did not reach
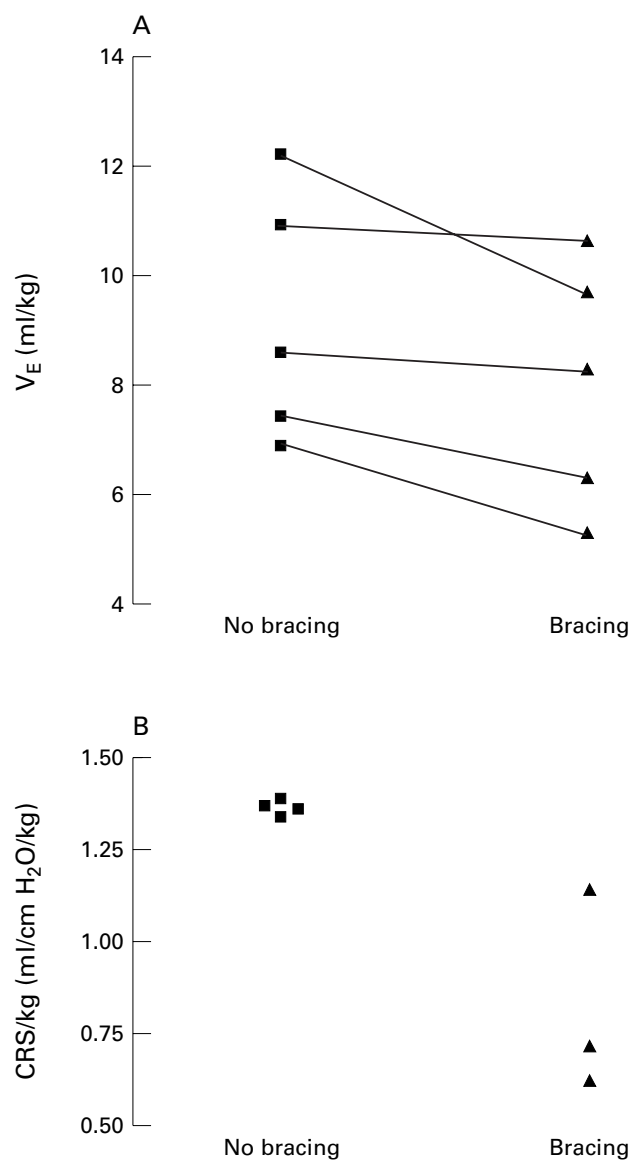

Sitting position

Figure 1 The effect of bracing on $(A)$ tidal expiratory volume $\left(V_{E}\right)$, and $(B)$ compliance of the respiratory system (CRS) in children with spinal muscular atrophy. statistical significance ( $p=0.068$; fig $1 B)$. The lowest value of CRS/kg was found in the two patients supine with bracing.

In several of the patients (fig 2), the flow volume loops were characterised by relatively early peak expiratory and inspiratory flows, as shown by a mean $t_{\mathrm{PTFF}} / t_{\mathrm{E}} 0.20-0.22$ compared to the normal loop.

\section{Discussion}

The present study showed that lung function within the tidal breathing range was adversely affected by rigid bracing in young children with SMA. There was a high $\mathrm{V}_{\mathrm{E}}$ as well as CRS/kg in the sitting compared to supine position.

\section{EFFECT OF BRACING}

In the present study, in children younger than 8 years with SMA, tidal volume was adversely affected by rigid bracing. This finding has not, to our knowledge, been described previously. In a study in 40 children with neuromuscular disease, Noble-Jamieson et al reported a reduction in forced vital capacity in children with most severe scoliosis. ${ }^{4}$ Ishida et al reported a correlation between vital capacity and tidal volume $^{14}$; the latter is reduced in children ${ }^{14}$ and adults ${ }^{15}$ with lower motor abilities. The finding that bracing, although possibly slowing down the progression of columnar deformity, reduced even tidal expiratory volume, may seriously affect ventilation.

The probability of a weakened diaphragm in those children most severely affected with SMA, may render the patients more dependent on active respiratory movements by the weakened intercostal muscles. Physical restriction of breathing within the tidal breathing range may thus render ventilation less than optimal. One patient in the present study (MS) was reassessed seven months later. She complained of restriction discomfort with a newly adjusted bracing, which was regarded optimal from an orthopaedic point of view. $\mathrm{V}_{\mathrm{E}}$ in the sitting position with bracing was $10.5 \mathrm{ml} / \mathrm{kg}$ (respiratory rate 42 breaths/min), and improved by almost $50 \%$ when the bracing was removed $\left(\mathrm{V}_{\mathrm{E}} / \mathrm{kg} 14.7 \mathrm{ml}\right.$, respiratory rate 28$)$. This is in accordance with the conclusion of the study by Noble-Jamieson and colleagues ${ }^{4}$ that spinal bracing causes appreciable respiratory impairment, and may explain why bracing is less likely to be tolerated in children with severe scoliosis.

CRS was higher in both the supine and sitting positions without bracing, compared to with bracing. However, because of the low number of subjects, statistical analysis is less relevant; CRS measurements were obtained only in two patients in the supine position with bracing. The lowest mean CRS was found in the supine position with bracing. There are, to our knowledge, no published reference ranges for passive respiratory mechanics in children within the age range of the present study. We cannot therefore assess the implications of the reported results in comparison to those of healthy individuals. The observed differences in CRS were not statistically significant, possibly as a result of the small number of subjects, but indicate an adverse effect of bracing on 

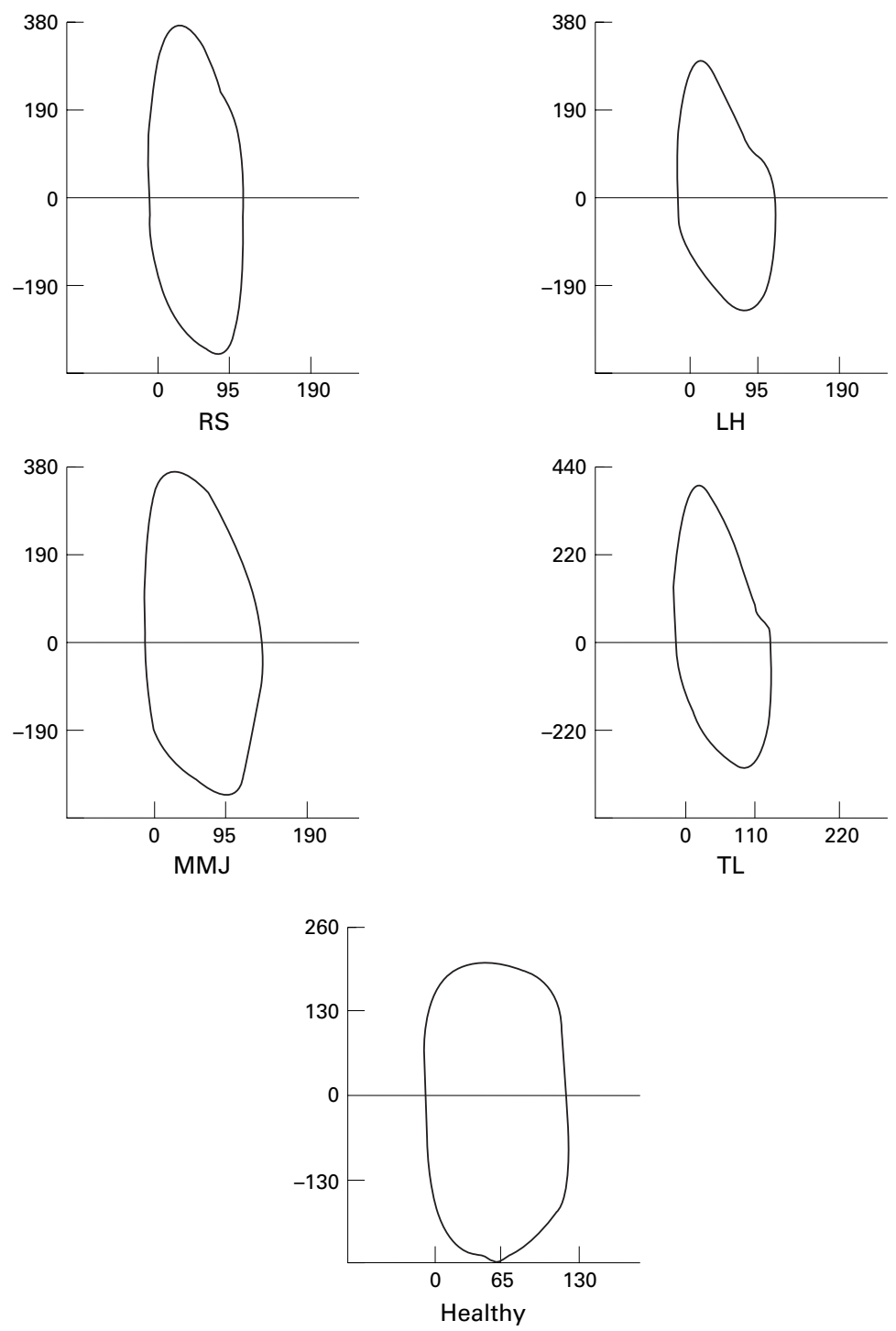

Figure 2 Tidal flow volume loops in four of the patients with spinal muscular atrophy as well as one healthy child aged 28 months (normal curve).

CRS (fig 2B). This is possible, as a progressive fall in lung ${ }^{16}$ and chest wall compliance ${ }^{17}$ is recognised in patients with muscle disease.

EFFECT OF POSTURE

$\mathrm{V}_{\mathrm{E}} / \mathrm{kg}$ and CRS were higher in the sitting compared to supine position (without bracing), although this did not reach statistical significance. A $6 \%$ fall in vital capacity, but without significant changes in forced expiratory flow, from sitting to supine position has been noted in children with a variety of neuromuscular diseases. ${ }^{4}$ Such decrease in lung function caused by postural changes has been reported to be a good indicator of diaphragmatic strength. ${ }^{4}$ We are not aware of any studies assessing possible effects of postural changes on tidal flow volume and passive respiratory mechanics. The higher $\mathrm{V}_{\mathrm{E}} / \mathrm{kg}$ (as well as CRS) in sitting compared to supine position may indicate that diaphragmatic strength can be assessed at a very early stage of disease, with relatively simple methodology. Further studies are, however, required to determine this.

TFV loops showed a pattern of a smaller ratio of peak expiratory as well as inspiratory flow to tidal volume, as well as a dissimilar shape of the expiratory part of the flow-volume curve in several of the patients, when compared to normal curves (fig 2). The reason for this is not known, and it is beyond the scope of the present paper to speculate on the underlying mechanisms. We did, however, observe reduced $t_{\mathrm{PTEF}} / t_{\mathrm{E}}$ (as can be seen in fig 1), and neither bracing nor position affected this parameter.

In conclusion, bracing caused impairment of tidal breathing lung function, and tidal volume and CRS tended to be higher in the sitting compared to supine position. Impairment of tidal respiration must be considered when adjusting bracing, and measures of tidal breathing parameters can be valuable in guiding such adjustments. When braces for patients with SMA are considered, it is clearly advisable for the respiratory team to be involved as well as the neurologist and orthopaedic surgeons.

1 Merlini L, Granata C, Bonfiglioli S, et al. Scoliosis in spinal muscular atrophy: natural history and management. Dev Med Child Neurol 1989;31:501-8.

2 Tangsrud S, Halvorsen S. Child neuromuscular disease in Southern Norway. Clin Genet 1988;34:145-52.

3 Dubowitz V. Muscle disease in childhood. Philadelphia: Saunders, 1978:253.

4 Noble-Jamieson CM, Heckmatt J, Dubowitz V, Silverman $M$. Effects of posture and spinal bracing on respiratory function in neuromuscular disease. Arch Dis Child 1986;61: 178-81.

5 Dollery CT, Gillam PMS, Hugh-Jones P, et al. Regional lung function in kyphoscoliosis. Thorax 1965;20:181A.

6 Schwentker EP, Gibson DA. The orthopaedic aspects of spinal muscular atrophy. F Bone foint Surg 1976;58A:32-8. Rodillo E, Marini M, Heckmatt J, Dubowitz V. Scoliosis in 7 Rodillo E, Marini M, Heckmatt J, Dubowitz V. Scoliosis in
spinal muscular atrophy: review of 63 cases. $f$ Child Neurol spinal muscular

8 Lødrup Carlsen KC. Tidal breathing analysis in infants and preschool children: tidal flow-volume loops. In: Zach $M$, Carlsen K-H, Warner JO, et al, eds. European Respiratory Monograph, No. 5. 1997:27-57.

9 Cobb JR. Outline for the study of scoliosis, instructional course lectures. No. 5. USA: American Academy of Orthopaedic Surgeons, 1948:261-75.

10 Medical Research Council. Aids to the investigation of peripheral nerve injuries. War Memorandum. London: His Majesty's Stationery Office, 1943:7.

11 Lødrup Carlsen KC, Carlsen KH. Lung function in awake healthy infants: the first five days of life. Eur Respir $\mathcal{F} 1993$; 6:1496-500.

12 Carlsen KH, Lødrup Carlsen KC. Tidal breathing analysis and response to salbutamol in awake young children with and response to salbutamol in awake young child

13 Lødrup KC, Mowinckel P, Carlsen KH. Lung function measurements in awake compared to sleeping newborn infants. Pediatr Pulmonol 1992;12:99-104.

14 Ishida C, Fujita M, Umemoto H, et al. Respiratory function in handicapped children. Brain Dev 1990;12:372-5.

15 Baydur A. Respiratory muscle strength and control of ventilation in patients with neuromuscular disease. Chest 1991; 99:330-8.

16 Gibson GJ, Pride NB. Pulmonary mechanisms in patients with respiratory muscle weakness. Thorax 1977;115:38995.

17 Hapke EJ. Pulmonary function in progressive muscular dystrophy. Chest 1972;61:41-7. 